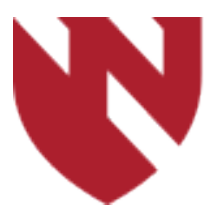

December 2020

\title{
Costs Associated with Recurrent Epistaxis in a Patient with a Ventricular Assist Device
}

\author{
Eric T. Rohe \\ University of Nebraska Medical Center \\ Evan M. Ryan \\ University of Nebraska Medical Center \\ Jayme R. Dowdall \\ University of Nebraska Medical Center \\ Dwight T. Jones \\ University of Nebraska Medical Center
}

Tell us how you used this information in this short survey.

Follow this and additional works at: https://digitalcommons.unmc.edu/gmerj

Part of the Otolaryngology Commons, and the Otorhinolaryngologic Diseases Commons

\section{Recommended Citation}

Rohe, ET, Ryan, EM, Dowdall, JR, Jones, DT. Costs Associated with Recurrent Epistaxis in a Patient with Ventricular Assist Device. Graduate Medical Education Research Journal. 2020 October 15.

This Case Report is brought to you for free and open access by DigitalCommons@UNMC. It has been accepted for inclusion in Graduate Medical Education Research Journal by an authorized editor of DigitalCommons@UNMC. For more information, please contact digitalcommons@unmc.edu. 


\title{
Costs Associated with Recurrent Epistaxis in a Patient with a Ventricular Assist Device
}

\begin{abstract}
Mucosal bleeding is a well-known complication of having a ventricular assist device and commonly presents with epistaxis. Although the frequency of epistaxis as a complication in patients with a ventricular assist device has been documented in the literature, to our knowledge the cost of this complication has not been reported. This case report examines the financial burden of ventricular assist device-associated epistaxis in a single patient from September 2018 to December 2019 using ICD 10 diagnostic codes. The patient was found to have accumulated $\$ 138,020$ in costs over 38 encounters. This case report not only highlights the recurrent nature and potential high cost of epistaxis in this patient population, but also identifies a target to reduce healthcare spending. Further research is needed to assess whether cheap and simple preventative measures such as nasal hygiene regimen can decrease the frequency and/or severity of epistaxis in the patients with a ventricular assist device.
\end{abstract}

\section{Keywords}

epistaxis, ventricular assist device, healthcare costs

\section{Creative Commons License}

cc) (i) $\Theta \Theta$

This work is licensed under a Creative Commons Attribution-Noncommercial-No Derivative Works 4.0 License.

\section{Cover Page Footnote}

None 


\title{
Costs Associated With Recurrent Epistaxis in a Patient With a Ventricular Assist Device
}

\author{
Eric T. Rohe ${ }^{1}$, Evan M. Ryan ${ }^{1}$, Jayme R. Dowdall', Dwight T. Jones ${ }^{1}$
}

${ }^{1}$ University of Nebraska Medical Center, Department of Otolaryngology- Head \& Neck Surgery, Omaha, NE

\begin{abstract}
Mucosal bleeding is a well-known complication of having a ventricular assist device and commonly presents with epistaxis. Although the frequency of epistaxis as a complication in patients with a ventricular assist device has been documented in the literature, to our knowledge the cost of this complication has not been reported. This case report examines the financial burden of ventricular assist device-associated epistaxis in a single patient from September 2018 to December 2019 using ICD 10 diagnostic codes. The patient was found to have accumulated $\$ 138,020$ in costs over 38 encounters. This case report not only highlights the recurrent nature and potential high cost of epistaxis in this patient population, but also identifies a target to reduce healthcare spending. Further research is needed to assess whether cheap and simple preventative measures such as nasal hygiene regimen can decrease the frequency and/ or severity of epistaxis in the patients with a ventricular assist device.
\end{abstract}

\section{Introduction}

Epistaxis is a well-documented complication of having a ventricular assistive device (VAD). Multiple factors, including dual anticoagulation/antiplatelet therapy and acquired clotting deficiencies contribute to mucosal bleeding. ${ }^{1}$ Studies have demonstrated that the most common presenting complaint to the emergency department in a patient with a VAD is mucosal bleedingg. ${ }^{2}$ While most otolaryngologists are aware of the frequency of epistaxis in this population, to our knowledge the cost of this complication has not been reported. In this case report, we document financial costs of epistaxis in a patient with a VAD over a 16-month period.

\section{Case Presentation}

A patient with a known history of mucosal bleeding was studied to examine the financial burdens of VAD-associated epistaxis. Using ICD codes, VAD-associated encounters were extracted from the patient's medical records over a 16-month period. The financial costs for each of these inpatient and outpatient encounters were obtained. Only the encounters associated with ICD 10 diagnosis of epistaxis or respiratory hemorrhage were included in the final analysis. Information regarding encounter type was extracted from the patient's medical record. All information extracted from this patient's medical records is in accordance with privacy standards set by Nebraska Medicine and the University of Nebraska Medical Center.

Analysis of clinic visits, emergency department visits, and inpatient management for this patient with a VAD revealed 38 total encounters to treat recurrent episodes of epistaxis. Of the 38 total encounters, fifteen of them were clinic visits resulting in $\$ 5,890$ in total costs. The patient was evaluated in discharged on nine occasions tallying $\$ 10,449$ in total costs. The patient was admitted in an inpatient setting 14 times over the course of the selected time period. These inpatient hospitalizations accrued $\$ 121,682$ in costs. Overall, the average total cost per inpatient hospitalization for epistaxis was $\$ 8,692$. Emergency department encounters averaged nearly $\$ 1200$ per visit. The mean total cost of

A.

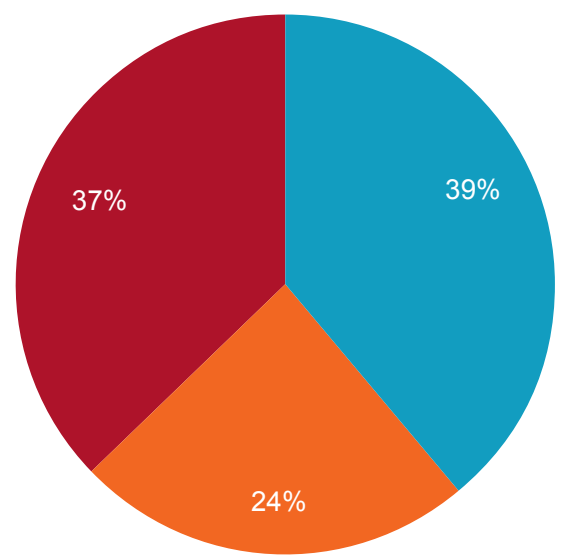
the emergency department and subsequently

each clinic encounter was $\$ 393$ (Figure 1 and Table 1).

\section{Discussion}

To our knowledge, this is the first report to outline the costs associated with epistaxis in patients with VADs. The studied patient presented to a tertiary care center 38 times over the course of a 16-month period for management of epistaxis. Over half of the encounters were in the emergency department $(61 \%)$, and the patient was admitted for inpatient management of epistaxis 14 times. The patient was evaluated 15 times in the clinic setting for management and followup of epistaxis. Unsurprisingly, inpatient hospitalization comprised the vast majority of total costs over the selected time period. The differences in costs between levels of care are expected, however, the number of encounters outside of a clinic setting shed light on the

B.

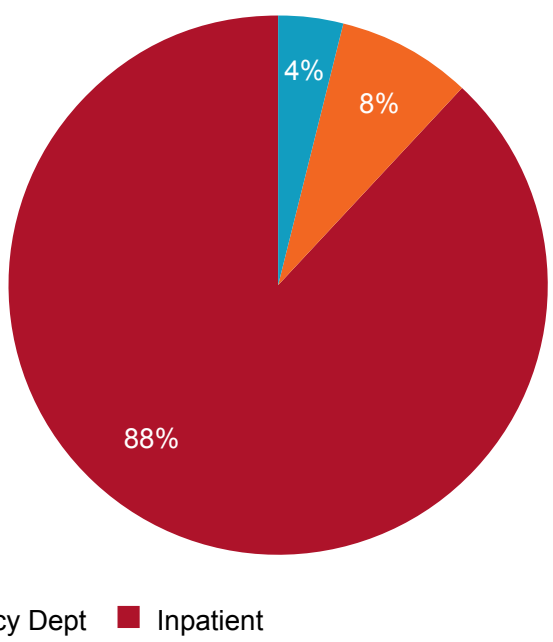

Figure 1. Proportion of encounter types and total costs associated with encounter types. (A) Proportions of each encounter type. Thirty-nine percent of all encounters over the 16-month period were in the clinic setting. Inpatient hospitalizations accounted for $37 \%$ of all encounters, whereas $24 \%$ of encounters were in the emergency department. (B) Proportion of total costs by encounter type. Inpatient hospitalizations accounted for $88 \%$ of the total costs. Emergency department and clinic encounters made up $8 \%$ and $4 \%$, respectively, of total costs accrued over the 16 -month period.

Table 1.

\begin{tabular}{lccc} 
& Number of Encounters & Cumulative Cost & Total cost/encounter \\
\hline Clinic & 15 & $\$ 5,890$ & $\$ 393$ \\
\hline Emergency Department & 9 & $\$ 10,449$ & $\$ 1,161$ \\
\hline Inpatient & 14 & $\$ 121,682$ & $\$ 8,692$ \\
\hline Total & $\mathbf{3 8}$ & $\$ \mathbf{1 3 8 , 0 2 0 2}$ & $\$ \mathbf{3 , 6 3 2}$
\end{tabular}


need for prevention of epistaxis in this patient population.

Previous studies have acknowledged the risk factors for VAD-associated epistaxis. ${ }^{1,3}$ Patients with VADs are placed on dual anticoagulation and antiplatelet therapy as their device acts as a nidus for thrombus formation. These medications are vital for the prevention of ventricular device failure secondary to pump thrombosis. Furthermore, the presence of the VAD leads to the mechanical destruction of von Willebrand factor, predisposing patients to bleeding dyscrasias. Healthcare providers are tasked with balancing the pro-coagulant effects of VAD with the complications of anticoagulation therapy.

The management of epistaxis in patients with VAD can be aimed at prevention of epistaxis occurrence or the acute intervention of an actively bleeding nose. In 2018, Brown et al. reviewed the various management options for acute intervention in patients with VADassociated epistaxis. Most notably, they found that the use of hemostatic agents, both dissolvable and non-dissolvable resulted in a lower likelihood of bleeding recurrence in comparison to those treated with silver nitrate cauterization. ${ }^{3}$ Despite conservative measures with nasal packing, vasoactive substances, and hemostatic agents, massive hemorrhage can ensue and become life-threatening, ultimately requiring surgical management. While endoscopic surgical ligation of the sphenopalatine artery is a commonly used approach, endovascular embolization procedures have been demonstrated to be similarly effective while being minimally invasive. $^{4}$

This case report highlights the importance of epistaxis prevention in patients with VADs. While nasal packing and vasoactive substances are useful in the management of acute bleeding, they do not prevent recurrence of bleeding. Similarly, hemostatic agents provide elements of short-term epistaxis prevention until they are removed or dissolved. The mainstay of epistaxis prevention in anticoagulated patients is the use of moisturizing agents, such as nasal saline gels and Vaseline. Although no control group was used for comparison, Massick et al. found that $93 \%$ of anticoagulated patients experienced cessation of their epistaxis at three months with use of nasal saline gel., ${ }^{5,6}$ Despite these findings, no research has been dedicated to evaluating the prevention of epistaxis in patients with VAD. Nasal hygiene measures are simple to use and cheap for patients in preventing epistaxis.
Although this case report does not delve into the specific interventions utilized at each encounter, it calls attention to the importance of preventative care in reducing healthcare burden and total healthcare costs.

\section{Conclusion}

The financial burden of epistaxis in anticoagulated patients can be astounding. This case report reviews the types of encounters and total costs associated with epistaxis in a patient with a VAD over a 16-month period. This case report identifies a potential target to reduce healthcare expenditures through the use of cheap and simple preventative nasal hygiene measures. Further research should be dedicated to elucidating the most effective options for prevention of epistaxis in this high-risk population.

https://doi.org/10.32873/unmc.dc.gmerj.2.2.009

\section{References}

1 Kurien S, Hughes KA. Anticoagulation and bleeding in patients with ventricular assist devices: walking the tightrope. AACN Adv Crit Care. 2012;23(1):91-8.

2 McKillip RP, Gopalsami A, Montoya M, Kim G, Walter JJ, Juricek C, Shappell E. Analysis of Patients with Ventricular Assist Devices Presenting to an Urban Emergency Department. West J Emerg Med. 2018;19(6):907-911.

3 Brown CS, Abi-Hachem R, Jang DW. Management of epistaxis in patients with ventricular assist device: a retrospective review. J Otolaryngol Head Neck Surg, 2018;47(1):48.

4 Letzen BS, Matouk CC, Bonde P. Particle embolization for the treatment of life-threatening epistaxis in a left ventricular assist device patient. ASAIO J. 2015;61(1):102-3

5 Smith J, Hanson J, Chowdhury R, Bungard T. Community-based management of epistaxis: Who bloody knows? Can Pharm J(Ott). 2019;152(3):164176.

6 Massick D, Hurtuk A. Effectiveness of a nasal saline gel in the treatment of recurrent anterior epistaxis in anticoagulated patients. Ear Nose Throat J. 2011;90(9):E4-6. 